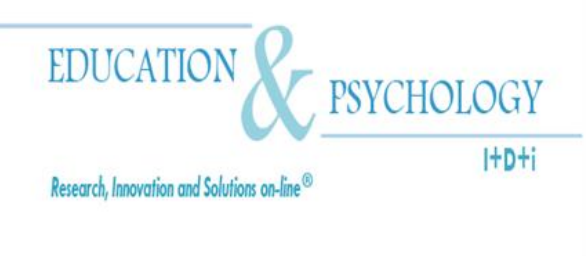

\title{
Aprendizaje del alumnado universitario de primer y último curso de las titulaciones de Psicología y Magisterio
}

\section{Lucía Herrera Torres ${ }^{1}$, Gracia Jiménez Fernández ${ }^{1}$, Ángel Castro Vázquez ${ }^{2}$}

${ }^{1}$ Dpto. Psicología Evolutiva y de la Educación, Universidad de Granada ${ }^{2}$ Dpto. Psicología y Sociología, Universidad de Zaragoza

\section{España}

Correspondencia: Lucía Herrera Torres. Universidad de Granada. Facultad de Educación y Humanidades del Campus Universitario de Meillla. C/ Santander, nº 1. 52071 Melilla, España. E-mail: luciaht@ugr.es

(C) Education \& Psychology I+D+i and Editorial EOS (Spain) 


\section{Resumen}

Introducción. Debido a la importancia que dentro del Espacio Europeo de Educación Superior se le ha otorgado al aprendizaje del alumnado universitario, el objetivo de este estudio es analizar las estrategias de aprendizaje de estudiantes universitarios en función de los estudios que realizan (Psicología-Magisterio) y del curso académico (primer y último curso).

Método. Participaron 888 estudiantes universitarios de cinco universidades españolas (Santiago de Compostela, Granada, Alicante, Jaén y Vigo), 408 estudiaban Psicología (192 primero y 216 quinto curso) y 480 Magisterio (272 primero y 208 tercero). Como instrumento de recogida de información se empleo el Cuestionario de Técnicas de Estudio (2006).

Resultados. Los resultados obtenidos muestran que los estudiantes de Magisterio mejoran sus estrategias de aprendizaje del primer al último curso, mientras que los estudiantes de Psicología muestran el patrón inverso, sobre todo en relación con el lugar y condiciones de estudio y con las estrategias de aprendizaje implementadas tanto antes como después del estudio.

Discusión y conclusiones. Los resultados convergentes y divergentes sobre las estrategias de aprendizaje de los estudiantes de las dos titulaciones y cursos analizados se discuten y se plantean diferentes temas relevantes a contemplar en futuras investigaciones.

Palabras Clave: Estrategias de aprendizaje, estudiantes universitarios, Psicología, Magisterio, primer y último curso 


\title{
Learning in university students in the first and last year of Psychology and Education degrees
}

\begin{abstract}
Introduction. Because of the relevance that the university students' learning has received in the European Higher Education Area, the aim of this study is to analyze the learning strategies of university students depending on the qualifications that they study (Psychology or Teaching Degree) and the academic course (first and last course).
\end{abstract}

Method. There took part 888 university students of five Spanish universities (Santiago de Compostela, Granada, Alicante, Jaen, and Vigo), 408 were studying Psychology Degree (192 in the first course and 216 in the fifth course) and 480 Teaching Degree (272 in first course and 208 in third course). The Study Techniques Questionnaire (2006) was used to collect the information.

Results. Results reveal that students of Teaching Degree improve their learning strategies of the first one to the last course, whereas the students of Psychology Degree show the reverse pattern, especially in relation with the place and conditions of study and with the learning strategies implemented both before and after the study.

Discussion and Conclusion. The convergent and divergent results on the learning strategies of the students of two analyzed qualifications and courses are discussed and different relevant topics that must be included in future researches.

Keywords: Learning strategies, University students, Psychology Degree, Teaching Degree, First and last course 


\section{Introducción}

Los recientes cambios que se están llevando a cabo en la educación superior para adaptar las enseñanzas universitarias oficiales al Espacio Europeo de Educación Superior (EEES) defienden un cambio en la concepción y modo de abordar el aprendizaje, pasando de los enfoques clásicos, centrados únicamente en el profesorado y en el proceso de enseñanza, a tener en consideración el contexto y el proceso de enseñanza-aprendizaje en su totalidad (De la Fuente y Justicia, 2007; Herrera, 2010). El principal protagonista del Proceso de Convergencia Europea es el estudiante (Fry, Ketteridge y Marshall, 2003; Herrera y Enrique, 2008), siendo una de las finalidades de la educación desarrollar las estrategias necesarias que le permitan aprender a aprender, incrementándose su autonomía personal y fomentando el pensamiento crítico y la reflexión sobre su propio proceso de aprendizaje (Benthan, 2002; Brockbank y McGill, 1998; Martín, Torbay, García y Rodríguez, 2002; Mayer, 2004; Mayor, Suengas y González, 1995; Zimmerman, 2000). Asimismo, el profesorado debe emplear estrategias y metodologías docentes que faciliten a los alumnos aprender a hacer y aprender de forma cooperativa junto a sus iguales (Delors, 1996; Gimeno y Pérez, 1999; Lizzio, Wilson y Simons, 2002; Moreira, 2000). Es por todo ello por lo que se está prestando mucha atención a las estrategias de aprendizaje de los alumnos, convirtiendo este campo en una de las líneas de investigación más potentes actualmente en la Psicología educativa (Cano, 2000; Valle, Barca, González y Núñez, 1999).

Existe mucha controversia entre los teóricos a la hora de definir el término "estrategias de aprendizaje", que en muchos estudios se emplea casi como sinónimo del término "hábitos de estudio" (Álvarez, 2008). Una de las definiciones más tradicionales y a la vez aceptadas es la de Nisbet y Shucksmith (1987), quienes entienden las estrategias de aprendizaje como secuencias integradas de procedimientos o actividades que se eligen con el propósito de facilitar la adquisición, el almacenamiento y la utilización de la información. Dicha definición es empleada también por otros autores como Cano (2000). En la misma dirección, Weinstein, Husman y Dierking (2000) señalan que las estrategias cognitivas o estrategias de aprendizaje integran pensamientos y comportamientos que facilitan la adquisición de información y su integración con los conocimientos previos ya existentes, así como la recuperación de la información disponible. Tras analizar distintas definiciones, Justicia y Cano (1993) concluyen que las estrategias de aprendizaje poseen varias características esenciales: son acciones que parten de la iniciativa del alumno, están formadas por una secuencia de actividades, se encuentran con- 
troladas por el sujeto que aprende y, en la mayoría de los casos, son deliberadas y planificadas por los propios estudiantes.

Desde otra aproximación más actual, se defiende una visión situada del aprendizaje, la cual postula una conexión ineludible entre lo que se aprende y los contextos en los que se aprende (Monereo, 1999a, 1999b). Por tanto, no se trata únicamente de que los alumnos adquieran cada vez un mayor conocimiento sobre qué deben hacer para aprender sino, especialmene, dónde, cúando, cómo y con quién deben hacerlo, de modo que se conviertan en aprendices estratégicos (Monereo, 1994, 2001; Monereo y Castelló, 1997) y, en definitiva, en aprendices autorregulados (Monereo, 2006; Zimmerman, 2002; Zimmerman y Kitsantas, 1997). Desde esta perspectiva, una estrategia de aprendizaje sería un proceso de toma de decisiones, consciente e intencional, que consiste en seleccionar los conocimientos conceptuales, procedimentales y actitudinales, necesarios para cumplimentar un determinado objetivo, siempre en función de las condiciones de la situación educativa en que se produce la acción (Monereo, 2000, p.34).

Dentro de las diferentes clasificaciones de las estrategias de aprendizaje, se pueden identificar tres grandes tipos de estrategias de aprendizaje (Pintrich y García, 1993; Pintrich, Smith, García y McKeachie, 1991):

a) Estrategias cognitivas, que incluyen las estrategias de repaso, elaboración y organización de la información, además del pensamiento crítico.

b) Estrategias metacognitivas, relativas a la planificación, el control y la regulación de las actividades que el sujeto realiza durante el aprendizaje.

c) Estrategias de regulación de recursos, las cuales se refieren a las estrategias de organización del tiempo y el ambiente de estudio, la regulación del esfuerzo, el aprendizaje con pares y la búsqueda de ayuda.

Por su parte, Carrasco (2004) identifica cinco componentes de las estrategias de aprendizaje: las estrategias por sí mismas, los procedimientos, las habilidades, las destrezas y los métodos y técnicas. En las estrategias estarían incluidos todos los demás, y se definirían como los diferentes modos de aprender antes, más y mejor; los procedimientos serían similares a las estrategias, entendidos como conjuntos de acciones ordenadas y dirigidas a la consecución de una meta; en cuanto a las habilidades, Schmeck (1988) afirma que son capacidades 
que pueden expresarse en cualquier momento, pues han sido interiorizadas a través de la práctica; es la misma definición que se puede dar a las destrezas; por último, los métodos y técnicas serían los medios utilizados para dirigir la actividad hacia el fin previsto siguiendo un orden determinado. Además, Justicia y Cano (1993) concluyen que el individuo que aprende no sólo requiere del dominio de las estrategias de aprendizaje, de sus componentes y de las técnicas que las componen, sino que también necesita una reflexión sobre los procesos y productos del conocimiento, así como conocer cómo se lleva a cabo el aprendizaje. Otros aspectos relevantes en relación con las estrategias de aprendizaje serían las estrategias de apoyo para conseguir el mayor rendimiento posible (Dansereau, 1985) y los procesos psicológicos requeridos para la aplicación de una estrategia, que para Valle et al. (1999) son cinco: habilidades o técnicas de estudio, metaconocimientos, conocimientos específicos, estrategias de apoyo y procesos básicos.

Las estrategias de aprendizaje se relacionan, además, con otros factores personales. Alonso (1995), por ejemplo, destaca el importante papel que juega la motivación en la forma de pensar y, por tanto, en el aprendizaje, por lo que un alumno con una alta motivación intrínseca selecciona y realiza las actividades por el interés y curiosidad que éstas le provocan. Igualmente, la motivación de los alumnos define su valoración e implicación en las tareas y actividades de aprendizaje (Wolters y Pintrich, 1998), sus sentimientos o creencias de autoeficacia (Pintrich y García, 1993), su control sobre el aprendizaje (Burón, 1995) y su nivel de ansiedad (Pintrich et al., 1991). Por lo tanto, la motivación es uno de los factores más importantes en relación con el uso correcto de las estrategias de aprendizaje; cuando una persona se siente autocompetente rinde más. Así, la autoestima y el autoconcepto también están directamente relacionados con el empleo de unas adecuadas estrategias de aprendizaje (Núñez et al., 1998).

Estrechamente relacionados con lo anteriormente descrito, los estilos de aprendizaje suponen la personalización o uso preferencial de unas determinadas estrategias de aprendizaje sobre otras. Suponen el lazo de unión entre la inteligencia y la personalidad (Camarero, Martín y Herrero, 2000; Sternberg, 1990), que quedará modelado por la forma determinada, por el estilo cognitivo, en que cada individuo organice y procese internamente la información (Riding y Rayner, 2000; Riding y Sadler, 1997). Al respecto, Marton y Booth (1997) distinguen, en función de la concepción que el propio alumno tenga sobre el aprendizaje y, por tanto, de las actividades que realice para logarlo, entre enfoques de aprendizaje superficiales, los 
cuales persiguen un incremento en el conocimiento y la repetición literal de la información, y profundos, centrados en la abstracción de significados y la comprensión de la realidad. Entwistle (2000) completa esta concepción sobre los enfoques de aprendizaje añadiendo una nueva dimensión, el enfoque estratégico, relativo a cómo el alumno organiza el tiempo y el esfuerzo de la manera más eficaz en función de cómo se perciban las demandas de la evaluación. De este modo, el grupo de Marton, partiendo de trabajos previos (Marton y Säljö, 1976; Säljö, 1979), establece seis concepciones diferentes que los alumnos universitarios pueden poner de manifiesto sobre el aprendizaje, las cuales varían dependiendo de si la concepción se centra en qué se aprende o en cómo se aprende, o se ponga el énfasis en los aspectos más estructurales e internos o en aquellos más referenciales o contextuales del aprendizaje (Marton, Dall’Alba y Beaty, 1993; Marton, Wen y Nagle, 1996):
A. El aprendizaje como incremento del conocimiento.
B. El aprendizaje como memorización y reproducción.
C. El aprendizaje como aplicación.
D. El aprendizaje como comprensión.
E. El aprendizaje como una forma diferente de ver las cosas.
F. El aprendizaje como cambio o desarrollo personal.

Tal y como señalan Mateos y Peñalba (2003), las prácticas evaluativas tradicionales en la educación superior pueden en alguna medida ser responsables del empleo, por parte del alumnado universitario, de un enfoque superficial de aprendizaje. Normalmente se les pide que lean para recordar, parafrasear o resumir lo que dicen los textos, pero no que apliquen y transformen las ideas contenidas en esos textos para poder extraer conclusiones, emitir juicios críticos o resolver problemas nuevos. De este modo, aunque la universidad debería ir más allá de la mera transmisión de conocimientos, persiguiendo la formación de estudiantes con un pensamiento crítico, que les permita el análisis y la reflexión sobre el mundo que les rodea para una mejor adaptación a los constantes cambios y demandas de la sociedad actual (Correa, Ceballos y Rodrigo, 2003), muchas de las aulas universitarias aún siguen siendo espacios de enseñanza unidireccional, donde el profesor transmite información y se espera que el alumnado, en el examen, reproduzca lo más fielmente los conocimientos que el profesor le transmitió (Pérez, Pozo y Rodríguez, 2003). No es extraño, por tanto, que la toma de apuntes sea la actividad a la que dedican más tiempo la mayoría de estudiantes universitarios (Castelló y Monereo, 1999; Monereo y Pérez-Cabaní, 1999). 
A la luz de estos resultados, es necesaria una reflexión sobre las condiciones en las que los alumnos aprenden puesto que, por lo general, poseen unas concepciones poco elaboradas sobre el aprendizaje, consideran que el conocimiento científico es incuestionable, difícilmente ponen de manifiesto capacidades de entender y adoptar distintos puntos de vista así como de argumentar por escrito, su motivación para aprender se centra en aprobar sin grandes esfuerzos, además de que piensan que los apuntes son la herramienta útil que les sirve para estudiar y aprobar (Alonso, 2001; Biggs, 2001; Huertas y Agudo, 2003; Martí, 2003).

La labor desarrollada por el profesorado universitario en el proceso de enseñanzaaprendizaje es uno de los aspectos a los que es necesario atender si se persigue que los estudiantes universitarios cambien sus concepciones y prácticas de aprendizaje. Pérez-Cabaní, Carretero, Palma y Rafel (2000) defienden que la enseñanza del uso estratégico de los procedimientos de aprendizaje incide directamente en la calidad del aprendizaje, por lo que es necesario atender a las características de la guía que ofrece el profesor como un factor determinante del resultado de este proceso; que la evaluación posee una función reguladora del aprendizaje puesto que las decisiones que tomen los estudiantes para gestionar el proceso de aprendizaje y estudio están condicionadas por las demandas de evaluación a las que han de enfrentarse; y, en tercer lugar, que la evaluación de la calidad del aprendizaje es un proceso complejo en el que, aunque todos los profesores están de acuerdo respecto a qué significa, a la hora de realizar una actividad de evaluación no existe un criterio común.

Puesto que el papel que juega el profesor universitario es un elemento clave en todo este proceso, han sido muchos los autores que han establecido y analizado las competencias docentes que ha de llevar a la práctica el profesorado universitario (Imbernón, 2004; Torrego, 2004; Zabalza, 2003, 2006). Así, por ejemplo, Zabalza (2003) identifica como competencias profesionales inherentes al desarrollo docente universitario las siguientes: la planificación del proceso de enseñanza-aprendizaje, la selección y preparación de los contenidos disciplinares, la oferta de informaciones y explicaciones comprensibles y bien organizadas (competencia comunicativa), el manejo de las tecnologías de la información y la comunicación, el diseño de las metodologías docentes y la organización de las actividades, la comunicación y relación con el alumnado, la tutorización, la evaluación, la reflexión e investigación sobre la enseñanza, la identificación con la institución y el trabajo en equipo. La formación del profesorado universitario para la docencia es, por todo ello, necesaria, dado que muchos profesores son 
especialistas en sus disciplinas pero no en la formación de aprendices reflexivos y críticos (Madrid, 2005; Marcelo, 2008; Margalef y Álvarez, 2005; Villar-Angulo, 2004).

A lo descrito hasta el momento es necesario añadir que las estrategias de aprendizaje que emplean los estudiantes universitarios y los resultados académicos que obtienen se encuentran estrechamente vinculados (De la Fuente et al., 2008; Garavalia y Gredler, 2002; Pintrinch, 2004), influyendo en esta relación variables de tipo tanto individual: edad, sexo, estilos de aprendizaje, motivación, autorregulación del aprendizaje, metas de aprendizaje, etc. (Bruinsma, 2004; Cano, 2000; Martín y Camarero, 2001; Valle, Cabanach, Rodríguez, Núñez y González-Pienda, 2006; Wolters, 2004), como contextual: la organización del plan de estudios universitario, los estilos de enseñanza del profesorado universitario y los métodos instruccionales empleados, entre otros (Cope y Staehr, 2005; Jansen, 2004; Trigwell, Prosser y Waterhouse, 1999). En este sentido, el modelo interactivo de enseñanza-aprendizaje DIDEPRO (acrónimo de DIseño, DEsarrollo, y PROducto), elaborado por De la Fuente y Justicia (2007), supone un modelo integrador de las variables y etapas que son necesarias analizar en este proceso, entendido como secuencial, interactivo e interdependiente, con la finalidad de que las tareas que han de llevar a cabo los agentes implicados, esto es, alumnado (aprender a aprender) y profesorado (enseñar a aprender), se definan y realicen con una mayor eficacia y calidad.

Entre los estudios que relacionan algunas de las variables descritas previamente se encuentra el de Camarero et al. (2000), quienes analizaron el uso que los universitarios hacen de las estrategias de aprendizaje en función del tipo de estudios, del curso y del rendimiento académico. Concluyeron que los alumnos de Humanidades (Magisterio y Derecho) frente a los de carreras técnicas y experimentales (Informática, Física y Matemáticas) utilizan más estrategias de aprendizaje, que realizan un estudio más profundo y basado en la interconexión de contenidos en los cursos finales y que los alumnos con mayor rendimiento académico emplean una mayor variedad de estrategias de aprendizaje con éxito. Esta última hipótesis también es apoyada por Martín, García, Torbay y Rodríguez (2008) en su estudio realizado con alumnos de Psicología y Psicopedagogía. Por su parte, García-Berbén (2005) concluye que los alumnos de mayor edad de las titulaciones de Magisterio y Psicopedagogía, que suelen estar en los cursos más avanzados de las titulaciones universitarias, utilizan un enfoque de aprendizaje más profundo que los más jóvenes, obteniendo mejores resultados académicos. Además, Martínez-Otero y Torres (2005), al analizar las estrategias de aprendizaje de alum- 
nos de primer curso de las titulaciones de Magisterio y Educación Social, encuentran que los alumnos de ambas titulaciones muestran una baja planificación del estudio, entendida como la confección de horarios y la organización del trabajo académico. Estos mismos resultados respecto a la falta de planificación del aprendizaje en los estudiantes de Magisterio son hallados por Herrera y Lorenzo (2009).

De la misma manera, en los últimos años está adquiriendo gran relevancia la comparación del uso de las estrategias de aprendizaje de los estudiantes universitarios en función del género. Martín y Camarero (2001) indican que las mujeres emplean, sobre todo, estrategias de adquisición y recuperación de la información (subrayado, agrupamiento de los contenidos, repaso), mientras que los hombres utilizan más la exploración previa, las relaciones intracontenido, las aplicaciones prácticas y el estudio teórico. Cano (2000) concluye que las alumnas muestran mayor miedo al fracaso en todos los estudios y que los alumnos, por su parte, expresan actitudes más negativas hacia el estudio. En el estudio realizado por García-Berbén (2005), con alumnos de la Universidad de Granada, se encuentra que las mujeres poseen estrategias de aprendizaje más profundas que los hombres.

En definitiva, la literatura científica señala la necesidad de analizar y desarrollar las estrategias de aprendizaje de los estudiantes universitarios (Amaya y Prado, 2007; Benthan, 2002; Camarero et al., 2000; Hattie, Biggs y Purdie, 1996; Martín et al., 2002), así como de diseñar e implementar en la universidad programas para mejorar la motivación de los estudiantes, haciéndoles más eficientes para ajustarse a diferentes contextos y manifestar un mayor compromiso e implicación personal en el aprendizaje (González, Valle, Rodríguez, García y Mendiri, 2007; Rozendal, Minnaert y Boekaerts, 2005). Como ponen de manifiesto diversos trabajos (Boekaerst, 1997; Boekaerst, Pintrich y Zeidner, 2000; De la Fuente, Pichardo, Justicia y García-Berbén, 2008; Heikkilä y Lonka, 2006; Winne, 1997; Zimmerman, 2000), la autorregulación durante el aprendizaje mejora la toma de conciencia y control sobre lo que se va a aprender y cómo se va a aprender e incrementa la calidad del aprendizaje así como el rendimiento académico.

\section{Objetivos}

Debido a la relevancia que en el panorama psicoeducativo actual tiene el estudio de las estrategias de aprendizaje del alumnado universitario, el objetivo de este estudio es analizar, 
en una muestra de estudiantes universitarios de diferentes universidades españolas en función de los estudios que realizan (Psicología-Magisterio) y del curso académico (comparando los alumnos de primer curso con los del último), las estrategias de aprendizaje que dicen emplear.

\section{Método}

\section{Participantes}

La muestra total estuvo compuesta por 888 estudiantes universitarios, de los cuales 408 estudiaban Psicología en las universidades de Santiago de Compostela y Granada $\left(N_{\text {primer }}\right.$ curso $=192,47.06 \%$ y $N_{\text {quinto }}$ curso $\left.=216,52.94 \%\right)$ y 480 cursaban Magisterio en las universidades de Alicante, Jaén, Vigo y Granada $\left(N_{\text {primer curso }}=272,56.66 \%\right.$ y $\left.N_{\text {tercer } \text { curso }}=208,43.34 \%\right)$. En la Tabla 1 se puede observar la distribución por sexo y edad en cada uno de los cursos (primero y último) y titulaciones (Psicología y Magisterio).

Tabla 1. Distribución de los participantes en función de las variables sexo (expresado en porcentaje) y edad (rango y promedio) en cada una de las titulaciones y cursos

\begin{tabular}{ccc}
\hline Psicología & Primero & Quinto \\
\hline Hombres & $20.3 \%(N=39)$ & $15.3 \%(N=33)$ \\
Mujeres & $79.7 \%(N=153)$ & $84.7 \%(N=183)$ \\
& $18-26$ & $21-36$ \\
Edad (rango y promedio) & 18.8 & 23.42 \\
$\mathrm{~N}$ & 192 & 216 \\
\hline Magisterio & Primero & Tercero \\
\hline Hombres & $22.5 \%(N=61)$ & $21.4 \%(N=45)$ \\
Mujeres & $77.5 \%(N=211)$ & $78.6 \%(N=163)$ \\
& $17-43$ & $20-45$ \\
Edad (rango y promedio) & 20.9 & 22.7 \\
$\mathrm{~N}$ & 272 & 208 \\
\hline
\end{tabular}

\section{Instrumentos}

Para el análisis de las estrategias de aprendizaje informadas por el alumnado se empleó el Cuestionario de Técnicas de Estudio, diseñado por Herrera y Gallardo (2006), el cual se estructura en torno a cuatro categorías o bloques de ítems. El primer bloque integra cuestiones relativas a los datos de identificación de los participantes: sexo, edad, titulación y especialidad, curso, vía de acceso a la universidad y si trabaja o no.

El segundo bloque de ítems se destina a conocer el lugar y condiciones de estudio del alumnado, debiendo indicar el lugar o lugares donde estudia (su habitación, salón, bibliote- 
ca...) así como las condiciones del lugar de estudio (luz, ruido, con ordenador, con música...). Tanto en este bloque como en los siguientes los alumnos debían contestar atendiendo a la siguiente escala tipo Likert: 1= Nunca; $2=$ A veces; $3=$ A menudo; 4= Siempre. En un tercer apartado se solicita información sobre cuestiones relacionadas con la organización del estudio, tales como si planifica el tiempo de estudio, si lo hace en función de los contenidos a estudiar, si organiza las asignaturas en función de su nivel de dificultad, si el estudio es continuo o se intensifica en el periodo cercano a los exámenes o las horas de estudio a la semana.

En el último bloque de ítems se recoge información sobre la frecuencia con que se emplean diferentes estrategias de aprendizaje antes, durante y después del estudio. Así, se pregunta por la frecuencia con que se memorizan los apuntes, se amplía la información aportada por el profesor, se realiza una lectura superficial antes de llevar a cabo una en mayor profundidad, si se acude al profesor en caso de dudas, el tipo de técnica de estudio que suele utilizar con mayor frecuencia (subrayado, esquemas, mapas conceptuales, ...), si se pone nervioso ante un examen, si repasa el examen una vez finalizado o si considera que las calificaciones obtenidas están directamente relacionadas con su trabajo y esfuerzo.

El cuestionario utilizado tiene una consistencia interna o fiabilidad, evaluada a través de la prueba estadística Alfa de Cronbach, de $\alpha=.72$. La fiabilidad para cada uno de los tres bloques de ítems que constituyen el cuestionario en sí, los bloques 2, 3 y 4, fue de .65, .67 y .82 , respectivamente. Respecto a su validez, el cuestionario cuenta con los requisitos exigidos de validez de contenido, habiéndose empleado en su validación la técnica de juicio de expertos. Como criterios para eliminar, modificar o aceptar los diferentes ítems del cuestionario se adoptaron los propuestos por Barbero, Vila y Suárez (2003).

\section{Procedimiento}

Durante los cursos académicos 2007-2008 y 2008-2009 se pasaron los cuestionarios en el horario habitual de clase de diferentes asignaturas pertenecientes a las dos titulaciones anteriormente mencionadas. Formaron parte de la muestra aquellos alumnos que, de forma voluntaria y anónima, así lo desearon, explicándoles previamente en qué consistía el cuestionario que debían cumplimentar. Del total de alumnos que estaba previsto que contestase al cuestionario, 1037 , finalmente contestaron de forma voluntaria 888 , esto es, el $85.63 \%$. 


\section{Análisis estadístico}

En primer lugar, para determinar los efectos de la Titulación y el Curso en las estrategias de aprendizaje del alumnado, se ha realizado un análisis de varianza con dos factores entregrupo (Titulación y Curso) y con la puntuación total obtenida en el cuestionario como variable dependiente. En segundo lugar, se ha realizado un análisis por ítem, a través de la prueba Chi-cuadrado, en aquellas categorías donde se observaron diferencias estadísticamente significativas entre el primer y el último curso en cada una de las titulaciones.

\section{Resultados}

Se ha realizado un estudio comparativo de la evolución de las estrategias de estudio que son utilizadas, según los estudiantes, por parte del alumnado de primer y último curso de la licenciatura de Psicología y la diplomatura de Magisterio con respecto a las tres categorías que aborda el cuestionario aplicado (lugar y condiciones de estudio; organización del estudio; y estrategias de aprendizaje implementadas antes, durante y después del estudio). Los resultados se obtuvieron a partir de la agrupación de las respuestas a los ítems en cada categoría; el bloque denominado "estrategias de aprendizaje" se subdividió en tres subcategorías referidas a las estrategias que utilizan los alumnos antes $(\alpha=.78)$, durante $(\alpha=.86)$ y después del estudio $(\alpha=.69)$. Esta subdivisión dio lugar a la obtención de cinco categorías (lugar y condiciones de estudio, organización del estudio, estrategias de aprendizaje antes del estudio, estrategias de aprendizaje durante el estudio y estrategias de aprendizaje después del estudio). La Tabla 2 muestra las puntuaciones medias y desviación típica en cada Titulación y Curso según las categorías señaladas.

Se llevó a cabo un análisis de varianza con dos factores entregrupo, Titulación (Psicología, Magisterio) y Curso (primer, último), siendo la variable dependiente la puntuación total de la prueba, es decir, la suma de las puntuaciones obtenidas en las cinco categorías del cuestionario utilizado, considerando que una frecuencia mayor es indicativa de mejores estrategias de aprendizaje. En aquellos ítems en los que este supuesto era inverso (por ejemplo, "Estudio sólo cuando se acercan los exámenes"), las puntuaciones se transformaron a la siguiente escala: $4=$ Nunca; $3=$ A veces; $2=$ A menudo; y $1=$ Siempre. 
Tabla 2. Media (y desviación típica) de las puntuaciones obtenidas en el cuestionario en función del Curso y la Titulación

\begin{tabular}{|c|c|c|c|c|c|c|}
\hline \multirow{2}{*}{ CATEGORÍAS } & \multicolumn{3}{|c|}{ PSICOLOGÍA } & \multicolumn{3}{|c|}{ MAGISTERIO } \\
\hline & Primero & Quinto & TOTAL & Primero & Tercero & TOTAL \\
\hline Lugar y condiciones de estudio & $\begin{array}{l}30.14 \\
(2.82)\end{array}$ & $\begin{array}{l}29.21 \\
(2.83)\end{array}$ & $\begin{array}{l}29.65 \\
(2.86)\end{array}$ & $\begin{array}{l}29.92 \\
(3.11)\end{array}$ & $\begin{array}{l}29.77 \\
(3.11)\end{array}$ & $\begin{array}{l}29.89 \\
(3.11)\end{array}$ \\
\hline Organización del estudio & $\begin{array}{l}26.20 \\
(4.05)\end{array}$ & $\begin{array}{l}26.01 \\
(4.47)\end{array}$ & $\begin{array}{l}26.10 \\
(4.27)\end{array}$ & $\begin{array}{l}25.73 \\
(4.98)\end{array}$ & $\begin{array}{l}25.44 \\
(5.21)\end{array}$ & $\begin{array}{l}25.68 \\
(5.02)\end{array}$ \\
\hline $\begin{array}{l}\text { Estrategias de aprendizaje antes } \\
\text { del estudio }\end{array}$ & $\begin{array}{l}13.20 \\
(1.47)\end{array}$ & $\begin{array}{l}13.71 \\
(1.47)\end{array}$ & $\begin{array}{l}13.47 \\
(1.49)\end{array}$ & $\begin{array}{l}13.01 \\
(1.58)\end{array}$ & $\begin{array}{l}13.48 \\
(1.34)\end{array}$ & $\begin{array}{l}13.08 \\
(1.55)\end{array}$ \\
\hline $\begin{array}{l}\text { Estrategias de aprendizaje durante } \\
\text { el estudio }\end{array}$ & $\begin{array}{l}46.83 \\
(4.88)\end{array}$ & $\begin{array}{l}46.49 \\
(5.34)\end{array}$ & $\begin{array}{l}46.65 \\
(5.12)\end{array}$ & $\begin{array}{l}46.69 \\
(5.31)\end{array}$ & $\begin{array}{l}47.43 \\
(5.78)\end{array}$ & $\begin{array}{l}46.82 \\
(5.40)\end{array}$ \\
\hline $\begin{array}{l}\text { Estrategias de aprendizaje después } \\
\text { del estudio }\end{array}$ & $\begin{array}{l}19.27 \\
(3.07)\end{array}$ & $\begin{array}{l}17.94 \\
(2.76)\end{array}$ & $\begin{array}{l}18.57 \\
(2.98)\end{array}$ & $\begin{array}{l}18.84 \\
(2.79)\end{array}$ & $\begin{array}{l}19.46 \\
(2.47)\end{array}$ & $\begin{array}{l}18.95 \\
(2.75)\end{array}$ \\
\hline TOTAL & $\begin{array}{l}135.64 \\
(10.14)\end{array}$ & $\begin{array}{l}133.36 \\
(9.97)\end{array}$ & $\begin{array}{l}134.43 \\
(10.10)\end{array}$ & $\begin{array}{l}134.17 \\
(11.62)\end{array}$ & $\begin{array}{l}135.58 \\
(11.88)\end{array}$ & $\begin{array}{l}134.42 \\
(11.67)\end{array}$ \\
\hline
\end{tabular}

Los resultados hallados mostraron que no eran significativos los efectos principales de los factores Titulación ni Curso $[F \mathrm{~s}<1]$ pero sí la interacción Titulación x Curso $\left[F_{(1,884)}=\right.$ 4.68, $p<.05]$. Como se puede observar en la Figura 1, los estudiantes de Magisterio parecen mejorar sus estrategias de aprendizaje del primer al último curso, mientras que los estudiantes de Psicología muestran el patrón inverso.

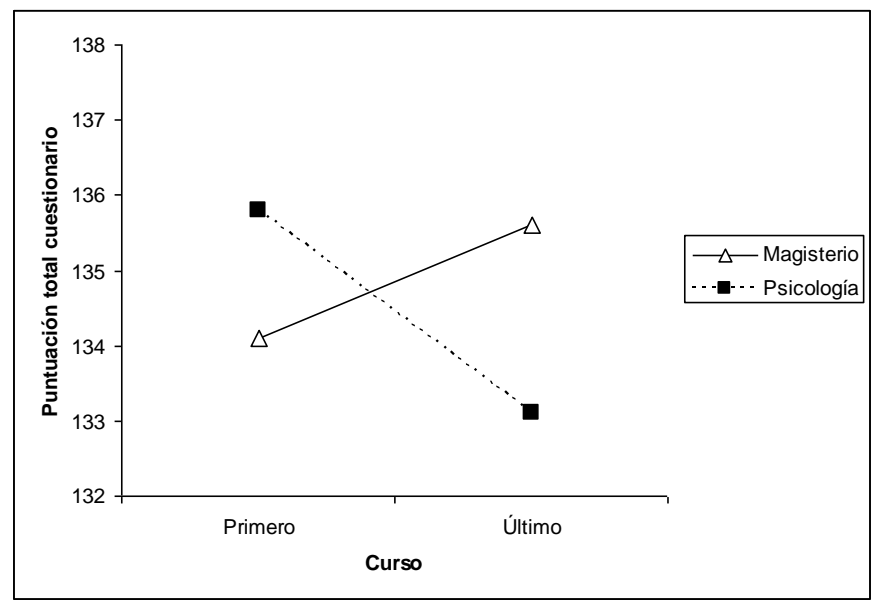

Figura 1. Puntuación media en el Cuestionario de Técnicas de Estudio según curso y titulación

La interacción observada apunta la necesidad de analizar cada titulación de forma independiente. Con respecto a la titulación de Psicología, existen diferencias entre cursos 
$\left[F_{(1,406)}=5.23, p<.05, \eta^{2}=.01\right]$, de modo que los estudiantes de primero muestran mejores estrategias de aprendizaje que los de último curso. A pesar de ello, como se puede apreciar, el tamaño del efecto es muy bajo. El análisis por categoría señala que estas diferencias aparecen específicamente en las categorías "Lugar y condiciones de estudio" $\left[F_{(1,406)}=11.05, p<.001\right.$, $\left.\eta^{2}=.03\right]$, "Estrategias de aprendizaje antes del estudio" $\left[F_{(1,406)}=11.97, p<.001, \eta^{2}=.03\right]$ y "Estrategias de aprendizaje después del estudio" $\left[F_{(1,406)}=20.91, p<.05, \eta^{2}=.05\right]$.

En el caso de la diplomatura de Magisterio, no se encuentran diferencias significativas entre los cursos $\left[F_{(1,478)}=1.01, p=.31 ; \eta^{2}=.002\right]$. No obstante, el análisis específico por categorías señala que los estudiantes de tercero muestran mejores hábitos que los de primero en las "Estrategias de aprendizaje antes del estudio" $\left[F_{(1,478)}=6.61, p<.05, \eta^{2}=.01\right]$. Además, se observa una tendencia en la categoría "Estrategias de aprendizaje después del estudio" $\left[F_{(1,478)}=3.56, p=.059, \eta^{2}=.007\right]$.

A partir de los resultados mencionados se ha realizado un análisis por ítem en aquellas categorías donde se observaron diferencias entre los cursos en cada una de las titulaciones. Estos análisis se realizaron a partir de la transformación en una escala dicotómica de la variable dependiente. Esta recodificación asignó el valor 0 (no frecuente) a los valores 1 y 2 de la escala original, y el valor 1 (frecuente) a los valores originales 3 y 4.

\section{Lugar y condiciones de estudio, en la licenciatura de Psicología}

En la Tabla 3 se muestran los porcentajes de respuesta en el bloque de ítems del cuestionario dirigido a examinar el lugar y condiciones de estudio, así como el análisis de frecuencias realizado mediante la prueba Chi-cuadrado. Como se puede observar, tanto en primer como en quinto curso de Psicología se observan diferencias estadísticamente significativas en todas las cuestiones relativas al lugar y condiciones de estudio. De este modo, los estudiantes en ambos cursos disponen habitualmente de un lugar fijo en casa para estudiar $(93.8 \%$ en primero y $84.7 \%$ en quinto), que suele ser su habitación ( $78.1 \%$ y $60.3 \%$, respectivamente), disponen de ordenador en dicho lugar (75.0\% en ambos cursos), y las condiciones ambientales son adecuadas respecto a la luz, preferentemente natural $(75.0 \%$ en primero y $79.2 \%$ en quinto), temperatura $(90.6 \%$ y $86.1 \%$ ) y ausencia de ruido $(98.4 \%$ y $91.5 \%)$. 
El análisis realizado para determinar si el lugar y las condiciones de estudio varían en función del curso mostró diferencias significativas en los ítems 1, 2, 4, 5, 6, 7 y 12. Así los estudiantes de primero se diferencian de los de quinto en que disponen más frecuentemente de un lugar fijo para el estudio (93.8\% frente a $84.7 \%$ en quinto; $\left.C h i^{2}=8.44, p<.05\right)$, suelen estudiar en su habitación $\left(78.1 \%\right.$ frente a $\left.60.3 \%, C h i^{2}=14.69, p<.01\right)$, no suelen estudiar en otra habitación de su casa $\left(93.0 \%\right.$ frente a $81.8 \%$; $\left.C h i^{2}=10.11, p<.01\right)$, tampoco en la biblioteca $\left(81.3 \%\right.$ y $69.4 \%$, respectivamente; $\left.C h i^{2}=7.56, p<.01\right)$ y el lugar de estudio no es ruidoso (98.4\% y $\left.91.5 \%, C h i^{2}=9.75, p<.01\right)$. Sin embargo, los alumnos de quinto curso no estudian en casa de un compañero o amigo (100\% en quinto frente a $96.9 \%$ en primero, $C h i^{2}=6.57, p<$ $.01)$ ni suelen compartir el lugar de estudio con nadie $\left(85.9 \%\right.$ frente a $78.1 \%, C h i^{2}=4.19, p<$ $.05)$.

Tabla 3. Porcentaje y Chi-Cuadrado de las cuestiones referidas al Lugar y Condiciones de Estudio, por curso, en la titulación de Psicología

\begin{tabular}{|c|c|c|c|c|c|c|c|}
\hline \multirow{2}{*}{$\begin{array}{l}\text { LUGAR Y CONDI- } \\
\text { CIONES DE ESTU- } \\
\text { DIO }\end{array}$} & \multicolumn{3}{|c|}{ Primer Curso } & \multicolumn{3}{|c|}{ Quinto Curso } & \multirow[b]{2}{*}{$C h i^{2}$} \\
\hline & $\begin{array}{l}\text { No Fre- } \\
\text { cuente }\end{array}$ & Frecuente & $C h i^{2}$ & $\begin{array}{l}\text { No Fre- } \\
\text { cuente }\end{array}$ & Frecuente & $C h i^{2}$ & \\
\hline $\begin{array}{l}\text { 1. Dispongo en casa de } \\
\text { un lugar fijo para estu- } \\
\text { diar }\end{array}$ & $\begin{array}{c}6.2 \% \\
(N=12)\end{array}$ & $\begin{array}{c}93.8 \% \\
(N=180)\end{array}$ & $147.00 *$ & $\begin{array}{l}15.3 \% \\
(N=33)\end{array}$ & $\begin{array}{c}84.7 \% \\
(N=183)\end{array}$ & $104.17 *$ & $8.44 *$ \\
\hline $\begin{array}{l}\text { 2. Estudio en mi habi- } \\
\text { tación }\end{array}$ & $\begin{array}{l}21.9 \% \\
(N=42)\end{array}$ & $\begin{array}{c}78.1 \% \\
(N=150)\end{array}$ & $60.75^{* *}$ & $\begin{array}{l}39.7 \% \\
(N=86)\end{array}$ & $\begin{array}{c}60.3 \% \\
(N=130)\end{array}$ & $8.65^{* *}$ & $14.69 * *$ \\
\hline $\begin{array}{l}\text { 3. Estudio en el salón } \\
\text { de mi casa }\end{array}$ & $\begin{array}{c}87.3 \% \\
(N=168)\end{array}$ & $\begin{array}{l}12.7 \% \\
(N=24)\end{array}$ & $105.19 * *$ & $\begin{array}{c}84.3 \% \\
(N=182)\end{array}$ & $\begin{array}{l}15.7 \% \\
(N=34)\end{array}$ & $98.74 * *$ & .74 \\
\hline $\begin{array}{l}\text { 4. Estudio en otra } \\
\text { habitación de mi casa }\end{array}$ & $\begin{array}{c}93.0 \% \\
(N=179)\end{array}$ & $\begin{array}{l}7.0 \% \\
(N=13)\end{array}$ & $126.37 * *$ & $\begin{array}{l}81.8 \% \\
(N=177)\end{array}$ & $\begin{array}{l}18.2 \% \\
(N=39)\end{array}$ & $80.19 * *$ & $10.11^{* *}$ \\
\hline $\begin{array}{l}\text { 5. Estudio en la biblio- } \\
\text { teca }\end{array}$ & $\begin{array}{l}81.2 \% \\
(N=156)\end{array}$ & $\begin{array}{l}18.8 \% \\
(N=36)\end{array}$ & $75.00 * *$ & $\begin{array}{c}69.4 \% \\
(N=150)\end{array}$ & $\begin{array}{l}30.6 \% \\
(N=66)\end{array}$ & $32.67 * *$ & $7.56^{* *}$ \\
\hline $\begin{array}{l}\text { 6. Estudio en casa de } \\
\text { un compañero/a o } \\
\text { amigo/a }\end{array}$ & $\begin{array}{c}96.9 \% \\
(N=186)\end{array}$ & $\begin{array}{l}3.1 \% \\
(N=6)\end{array}$ & $168.75^{* *}$ & $\begin{array}{l}100.0 \% \\
(N=216)\end{array}$ & $\begin{array}{c}.0 \% \\
(N=0)\end{array}$ & - & $6.57 * *$ \\
\hline $\begin{array}{l}\text { 7. El lugar donde estu- } \\
\text { dias ¿lo compartes con } \\
\text { alguien? }\end{array}$ & $\begin{array}{c}78.1 \% \\
(N=150)\end{array}$ & $\begin{array}{l}21.9 \% \\
(N=42)\end{array}$ & $60.75^{* *}$ & $\begin{array}{c}85.9 \% \\
(N=186)\end{array}$ & $\begin{array}{l}14.1 \% \\
(N=30)\end{array}$ & $109.90 * *$ & $4.19 *$ \\
\hline $\begin{array}{l}\text { 8. Tengo ordenador en } \\
\text { mi lugar habitual de } \\
\text { estudio }\end{array}$ & $\begin{array}{l}25.0 \% \\
(N=48)\end{array}$ & $\begin{array}{c}75.0 \% \\
(N=144)\end{array}$ & $48.00 * *$ & $\begin{array}{l}25.0 \% \\
(N=54)\end{array}$ & $\begin{array}{c}75.0 \% \\
(N=162)\end{array}$ & $54.00 * *$ & .00 \\
\hline $\begin{array}{l}\text { 9. Me gusta estudiar } \\
\text { cerca de la ventana }\end{array}$ & $\begin{array}{l}25.0 \% \\
(N=48)\end{array}$ & $\begin{array}{c}75.0 \% \\
(N=144)\end{array}$ & $48.00 * *$ & $\begin{array}{l}20.8 \% \\
(N=45)\end{array}$ & $\begin{array}{c}79.2 \% \\
(N=171)\end{array}$ & $73.50 * *$ & 1.01 \\
\hline $\begin{array}{l}\text { 10. Estudio con luz } \\
\text { artificial (flexo o } \\
\text { lámpara) }\end{array}$ & $\begin{array}{l}35.8 \% \\
(N=69)\end{array}$ & $\begin{array}{c}64.2 \% \\
(N=123)\end{array}$ & $15.1 \mathrm{C}$ & $\begin{array}{l}38.9 \% \\
(N=84)\end{array}$ & $\begin{array}{c}61.1 \% \\
(N=132)\end{array}$ & $10.67 * *$ & .38 \\
\hline $\begin{array}{l}\text { 11. En mi lugar de } \\
\text { estudio hace una tem- } \\
\text { peratura agradable }\end{array}$ & $\begin{array}{c}9.4 \% \\
(N=18)\end{array}$ & $\begin{array}{c}90.6 \% \\
(N=174)\end{array}$ & $126.75^{* *}$ & $\begin{array}{l}13.9 \% \\
(N=30)\end{array}$ & $\begin{array}{c}86.1 \% \\
(N=186)\end{array}$ & $112.67 * *$ & 1.99 \\
\hline $\begin{array}{l}\text { 12. El lugar donde } \\
\text { estudio es ruidoso }\end{array}$ & $\begin{array}{c}98.4 \% \\
(N=189)\end{array}$ & $\begin{array}{l}1.6 \% \\
(N=3)\end{array}$ & 180.1 & $\begin{array}{c}91.5 \% \\
(N=198)\end{array}$ & $\begin{array}{c}8.5 \% \\
(N=18)\end{array}$ & $147.08 * *$ & $9.75 * *$ \\
\hline 13. Estudio viendo o & $98.4 \%$ & $1.6 \%$ & $180.19 * *$ & $95.8 \%$ & $4.2 \%$ & $181.50 * *$ & 2.41 \\
\hline
\end{tabular}




\begin{tabular}{|c|c|c|c|c|c|c|c|}
\hline $\begin{array}{l}\text { escuchando la televi- } \\
\text { sión }\end{array}$ & $(N=189)$ & $(N=3)$ & & $(N=207)$ & $(N=9)$ & & \\
\hline $\begin{array}{l}\text { 14. Estudio escuchan- } \\
\text { do música }\end{array}$ & $\begin{array}{c}93.7 \% \\
(N=180)\end{array}$ & $\begin{array}{c}6.3 \% \\
(N=12)\end{array}$ & $147.00 * *$ & $\begin{array}{c}94.3 \% \\
(N=204)\end{array}$ & $\begin{array}{c}5.7 \% \\
(N=12)\end{array}$ & $164.74 * *$ & .05 \\
\hline $\begin{array}{l}\text { 15. Con frecuencia } \\
\text { estudio o leo recostado } \\
\text { en la cama o tumbado } \\
\text { en el sofá }\end{array}$ & $\begin{array}{l}70.3 \% \\
(N=135)\end{array}$ & $\begin{array}{l}29.7 \% \\
(N=57)\end{array}$ & $31.69^{* *}$ & $\begin{array}{c}70.8 \% \\
(N=153)\end{array}$ & $\begin{array}{l}29.2 \% \\
(N=63)\end{array}$ & $37.50 * *$ & .01 \\
\hline
\end{tabular}

${ }^{*} p<.05, * * p<.01$

\section{Estrategias de aprendizaje antes del estudio, en la licenciatura de Psicología}

El análisis de frecuencias con respecto a las estrategias de aprendizaje antes del estudio que usan los estudiantes de primero (ver Tabla 4) mostró diferencias significativas en todos los ítems excepto en el referido a copiar los apuntes al pie de la letra (no frecuente $43.8 \%$ $v s$. frecuente $56.3 \%$ ). En general, estos estudiantes frecuentemente toman apuntes en las clases $(89.1 \%)$, no fotocopian los apuntes de otro compañero $(81.3 \%)$, no suelen ampliar información con bibliografía complementaria $(82.8 \%)$ y no tienen dificultades para seguir las explicaciones del profesorado en clase $(98.4 \%)$.

Por su parte, el análisis de las respuestas de los estudiantes de quinto mostró diferencias en todos los ítems. De esta manera, es frecuente que tomen apuntes de las explicaciones del profesor (87.3\%), no fotocopian los apuntes de otros compañeros $(60.6 \%)$ ni toman apuntes copiando literalmente lo que dice el profesor (59.2\%), no suelen ampliar la información con bibliografía complementaria $(95.8 \%)$ y es destacable el hecho de que ningún alumno de quinto suela mostrar dificultades para seguir las explicaciones del profesor.

El análisis llevado a cabo en función del curso mostró diferencias significativas en todos los ítems, excepto en el 29 y 33. Así, estos resultados indican que los estudiantes de quinto fotocopian los apuntes de otros compañeros en mayor medida que los de primero $(39.4 \%$ en quinto frente a $18.8 \%$ en primero, $C h i^{2}=20.73, p<.01$ ), mientras que los de primero toman apuntes copiando al pie de la letra la explicación del profesor (56.3\% en primero frente a $40.8 \%$ en quinto, $\left.C h i^{2}=9.59, p<.01\right)$ y amplían la información con bibliografía complementaria $\left(17.2 \%\right.$ en primero frente a $4.2 \%$ en quinto, $\left.C h i^{2}=18.25, p<.01\right)$. 
Tabla 4. Porcentaje y Chi-Cuadrado de las cuestiones referidas a las Estrategias de Aprendizaje antes del estudio, por curso, en la titulación de Psicología

\begin{tabular}{|c|c|c|c|c|c|c|c|}
\hline \multirow{2}{*}{$\begin{array}{l}\text { ESTRATEGIAS DE } \\
\text { APRENDIZAJE ANTES } \\
\text { DEL ESTUDIO }\end{array}$} & \multicolumn{3}{|c|}{ Primer Curso } & \multicolumn{3}{|c|}{ Quinto Curso } & \multirow[b]{2}{*}{$C h i^{2}$} \\
\hline & $\begin{array}{l}\text { No Fre- } \\
\text { cuente }\end{array}$ & Frecuente & $C h i^{2}$ & $\begin{array}{c}\text { No Fre- } \\
\text { cuente }\end{array}$ & Frecuente & $C h i^{2}$ & \\
\hline $\begin{array}{l}\text { 29. Tomo apuntes de las } \\
\text { explicaciones de los pro- } \\
\text { fesores/as }\end{array}$ & $\begin{array}{c}10.9 \% \\
(N=21)\end{array}$ & $\begin{array}{c}89.1 \% \\
(N=171)\end{array}$ & $117.19 * *$ & $\begin{array}{l}12.7 \% \\
(N=27)\end{array}$ & $\begin{array}{c}87.3 \% \\
(N=189)\end{array}$ & $118.69 * *$ & .29 \\
\hline $\begin{array}{l}\text { 30. Fotocopio los apuntes } \\
\text { de algún compañero o } \\
\text { compañera }\end{array}$ & $\begin{array}{c}81.2 \% \\
(N=156)\end{array}$ & $\begin{array}{l}18.8 \% \\
(N=36)\end{array}$ & $75.00 * *$ & $\begin{array}{c}60.6 \% \\
(N=131)\end{array}$ & $\begin{array}{l}39.4 \% \\
(N=85)\end{array}$ & $9.51 * *$ & $20.73 * *$ \\
\hline $\begin{array}{l}\text { 31. Cuando tomo apuntes } \\
\text { copio al pie de la letra lo } \\
\text { que dice el profesor/a }\end{array}$ & $\begin{array}{l}43.7 \% \\
(N=84)\end{array}$ & $\begin{array}{c}56.3 \% \\
(N=108)\end{array}$ & 3.00 & $\begin{array}{c}59.2 \% \\
(N=128)\end{array}$ & $\begin{array}{l}40.8 \% \\
(N=88)\end{array}$ & $7.14 * *$ & $9.59 * *$ \\
\hline $\begin{array}{l}\text { 32. Amplío la información } \\
\text { con bibliografía comple- } \\
\text { mentaria }\end{array}$ & $\begin{array}{c}82.8 \% \\
(N=159)\end{array}$ & $\begin{array}{l}17.2 \% \\
(N=33)\end{array}$ & $82.69 * *$ & $\begin{array}{c}95.8 \% \\
(N=207)\end{array}$ & $\begin{array}{l}4.2 \% \\
(N=9)\end{array}$ & $178.52 * *$ & $18.25^{* *}$ \\
\hline $\begin{array}{l}\text { 33. Tengo dificultades en } \\
\text { seguir las explicaciones } \\
\text { del profesor/a en clase }\end{array}$ & $\begin{array}{c}98.4 \% \\
(N=189)\end{array}$ & $\begin{array}{l}1.6 \% \\
(N=3)\end{array}$ & $180.19 * *$ & $\begin{array}{l}100.0 \% \\
(N=216)\end{array}$ & $\begin{array}{c}.0 \% \\
(N=0)\end{array}$ & - & 3.35 \\
\hline
\end{tabular}
${ }^{*} p<.05, * * p<.01$

Estrategias de aprendizaje después del estudio, en la licenciatura de Psicología

Como muestra la Tabla 5, en el análisis de las estrategias de aprendizaje después del estudio en los estudiantes de primer curso se hallaron diferencias significativas en todos los ítems. El 60.9\% de los alumnos participantes indica que suele recordar lo estudiado después del examen, el $58.1 \%$ que se pone nervioso cuando tiene un examen, el $64.1 \%$ que no suele comenzar a contestar la primera pregunta del examen sin leer el resto, el 77.8\% repasa el examen antes de entregarlo, el 59.4\% que no suele comprobar al salir del examen las respuestas dadas con los apuntes, el $62.5 \%$ que consideró que las calificaciones obtenidas están relacionadas con su estudio y esfuerzo y, por último, el $81.3 \%$ que está satisfecho con las calificaciones obtenidas en el último curso realizado.

Por su parte, el análisis llevado a cabo en quinto curso señaló diferencias significativas en cuatro de los siete ítems de esta categoría. En este sentido, el 76.4\% del alumnado de quinto repasa el examen antes de ser entregado, el 69.4\% no comprueba las respuestas del examen al salir del mismo, el $56.9 \%$ considera que las calificaciones se deben a su estudio y esfuerzo y, en cuarto lugar, el $62.5 \%$ está satisfecho con las calificaciones obtenidas el curso anterior. Sin embargo, no existen diferencias significativas entre la frecuencia o ausencia de recordar lo 
estudiado después del examen, ponerse nervioso al tener un examen ni comenzar un examen por la primera pregunta sin leer el resto.

El análisis realizado en función de curso halló diferencias significativas en los ítems $51,53,55$ y 57 , de modo que los alumnos de primero recuerdan en mayor medida que los de quinto lo estudiado $\left(60.9 \%\right.$ en primero frente a $47.9 \%$ en quinto, $\left.C h i^{2}=6.93, p<.01\right)$, no contestan al examen hasta leerlo todo $\left(64.1 \%\right.$ frente a $\left.51.4 \%, C h i^{2}=6.68, p<.05\right)$ y están más satisfechos con las calificaciones obtenidas el último curso $\left(81.3 \%\right.$ vs. $62.5 \%, C^{2} i^{2}=17.47, p<$ .01). Los alumnos de quinto, por su parte, comprueban en menor medida que los de primero las respuestas dadas con los apuntes al salir del examen $(69.4 \%$ en quinto frente a $59.4 \%$ en primero, $\left.C h i^{2}=4.51, p<.05\right)$.

Tabla 5. Porcentaje y Chi-Cuadrado de las cuestiones referidas a las Estrategias de Aprendizaje después del estudio, por curso, en la titulación de Psicología

\begin{tabular}{|c|c|c|c|c|c|c|c|}
\hline \multirow{2}{*}{$\begin{array}{l}\text { ESTRATEGIAS DE } \\
\text { APRENDIZAJE DES- } \\
\text { PUÉS DEL ESTUDIO }\end{array}$} & \multicolumn{3}{|c|}{ Primer Curso } & \multicolumn{3}{|c|}{ Quinto Curso } & \multirow[b]{2}{*}{$C h i^{2}$} \\
\hline & $\begin{array}{l}\text { No Fre- } \\
\text { cuente }\end{array}$ & Frecuente & $C h i^{2}$ & $\begin{array}{l}\text { No Fre- } \\
\text { cuente }\end{array}$ & Frecuente & $C h i^{2}$ & \\
\hline $\begin{array}{l}\text { 51. Suelo recordar lo } \\
\text { estudiado después del } \\
\text { examen }\end{array}$ & $\begin{array}{c}39.1 \% \\
(N=75)\end{array}$ & $\begin{array}{c}60.9 \% \\
(N=117)\end{array}$ & $9.19 * *$ & $\begin{array}{c}52.1 \% \\
(N=113)\end{array}$ & $\begin{array}{c}47.9 \% \\
(N=103)\end{array}$ & .38 & $6.93 * *$ \\
\hline $\begin{array}{l}\text { 52. Cuando tengo un } \\
\text { examen me pongo nervio- } \\
\text { so/a }\end{array}$ & $\begin{array}{l}41.9 \% \\
(N=80)\end{array}$ & $\begin{array}{c}58.1 \% \\
(N=112)\end{array}$ & $4.84 *$ & $\begin{array}{c}48.6 \% \\
(N=105)\end{array}$ & $\begin{array}{c}51.4 \% \\
(N=111)\end{array}$ & .17 & 1.79 \\
\hline $\begin{array}{l}\text { 53. Cuando realizo un } \\
\text { examen comienzo por la } \\
\text { primera pregunta sin leer } \\
\text { el resto }\end{array}$ & $\begin{array}{c}64.1 \% \\
(N=123)\end{array}$ & $\begin{array}{l}35.9 \% \\
(N=69)\end{array}$ & $15.19 * *$ & $\begin{array}{c}51.4 \% \\
(N=111)\end{array}$ & $\begin{array}{c}48.6 \% \\
(N=105)\end{array}$ & .17 & $6.68 *$ \\
\hline $\begin{array}{l}\text { 54. Repaso el examen } \\
\text { antes de entregarlo al } \\
\text { profesor/a }\end{array}$ & $\begin{array}{l}22.2 \% \\
(N=43)\end{array}$ & $\begin{array}{c}77.8 \% \\
(N=149)\end{array}$ & $58.33 * *$ & $\begin{array}{l}23.6 \% \\
(N=51)\end{array}$ & $\begin{array}{c}76.4 \% \\
(N=165)\end{array}$ & $60.17 * *$ & .11 \\
\hline $\begin{array}{l}\text { 55. Al salir de un examen } \\
\text { compruebo con los apun- } \\
\text { tes las respuestas que he } \\
\text { dado }\end{array}$ & $\begin{array}{c}59.4 \% \\
(N=114)\end{array}$ & $\begin{array}{l}40.6 \% \\
(N=78)\end{array}$ & $6.75 * *$ & $\begin{array}{c}69.4 \% \\
(N=150)\end{array}$ & $\begin{array}{l}30.6 \% \\
(N=66)\end{array}$ & $32.67 * *$ & $4.51 *$ \\
\hline $\begin{array}{l}\text { 56. Considero que las } \\
\text { calificaciones obtenidas } \\
\text { están en función de mi } \\
\text { estudio y esfuerzo }\end{array}$ & $\begin{array}{l}37.5 \% \\
(N=72)\end{array}$ & $\begin{array}{c}62.5 \% \\
(N=120)\end{array}$ & $12.00 * *$ & $\begin{array}{l}43.1 \% \\
(N=93)\end{array}$ & $\begin{array}{c}56.9 \% \\
(N=123)\end{array}$ & $4.17 *$ & 1.31 \\
\hline $\begin{array}{l}\text { 57. Estoy satisfecho con } \\
\text { las calificaciones que he } \\
\text { obtenido en el curso ante- } \\
\text { rior (o ultimo curso que } \\
\text { estudiaste) }\end{array}$ & $\begin{array}{c}18.8 \% \\
(N=36)\end{array}$ & $\begin{array}{c}81.2 \% \\
(N=156)\end{array}$ & $75.00 * *$ & $\begin{array}{c}37.5 \% \\
(N=81)\end{array}$ & $\begin{array}{c}62.5 \% \\
(N=135)\end{array}$ & $13.5 * *$ & $17.47 * *$ \\
\hline
\end{tabular}

Estrategias de aprendizaje antes del estudio, en la diplomatura de Magisterio 
La Tabla 6 muestra las estrategias de aprendizaje utilizadas antes del estudio. Tanto en el primer como en el último curso se obtienen diferencias estadísticamente significativas entre las frecuencias en cada ítem de esta categoría. Así, los estudiantes de ambos cursos suelen tomar apuntes de las explicaciones del profesor en clase $(80.9 \%$ en primero y $76.2 \%$ en tercero), no fotocopian los apuntes de ningún compañero (79.7\% y $63.9 \%$, respectivamente) ni es frecuente que tomen apuntes copiando al pie de la letra lo dicho por el profesor $(64.8 \% \mathrm{y}$ $75.9 \%$ ), tampoco suelen ampliar la información a estudiar con bibliografía complementaria (90.0\% y 89.0\%) ni experimentan dificultades para seguir las explicaciones del profesor en clase $(96.7 \%$ y $98.8 \%)$.

El análisis en función del curso sólo mostró diferencias significativas en el ítem 30 ya que la frecuencia de uso de los apuntes de un compañero aumenta de primero a tercero (de $20.3 \%$ a $\left.36.1 \% ; C h i^{2}=9.78, p<.01\right)$.

Tabla 6. Porcentaje y Chi-Cuadrado de las cuestiones referidas a las Estrategias de Aprendizaje antes del estudio, por curso, en la diplomatura de Magisterio

\begin{tabular}{|c|c|c|c|c|c|c|c|}
\hline \multirow{2}{*}{$\begin{array}{l}\text { ESTRATEGIAS DE } \\
\text { APRENDIZAJE ANTES } \\
\text { DEL ESTUDIO }\end{array}$} & \multicolumn{3}{|c|}{ Primer Curso } & \multicolumn{3}{|c|}{ Tercero Curso } & \multirow[t]{2}{*}{$C h i^{2}$} \\
\hline & $\begin{array}{l}\text { No Fre- } \\
\text { cuente }\end{array}$ & Frecuente & $C h i^{2}$ & $\begin{array}{l}\text { No Fre- } \\
\text { cuente }\end{array}$ & Frecuente & $C h i^{2}$ & \\
\hline $\begin{array}{l}\text { 29. Tomo apuntes de las } \\
\text { explicaciones de los pro- } \\
\text { fesores/as }\end{array}$ & $\begin{array}{l}19.1 \% \\
(N=52)\end{array}$ & $\begin{array}{c}80.9 \% \\
(N=220)\end{array}$ & $150.25^{* *}$ & $\begin{array}{l}23.8 \% \\
(N=50)\end{array}$ & $\begin{array}{c}76.2 \% \\
(N=158)\end{array}$ & $23.05 * *$ & .97 \\
\hline $\begin{array}{l}\text { 30. Fotocopio los apuntes } \\
\text { de algún compañero o } \\
\text { compañera }\end{array}$ & $\begin{array}{c}79.7 \% \\
(N=217)\end{array}$ & $\begin{array}{l}20.3 \% \\
(N=55)\end{array}$ & $139.81 * *$ & $\begin{array}{c}63.9 \% \\
(N=133)\end{array}$ & $\begin{array}{l}36.1 \% \\
(N=75)\end{array}$ & $6.37 *$ & $9.78 * *$ \\
\hline $\begin{array}{l}\text { 31. Cuando tomo apuntes } \\
\text { copio al pie de la letra lo } \\
\text { que dice el profesor/a }\end{array}$ & $\begin{array}{c}64.8 \% \\
(N=176)\end{array}$ & $\begin{array}{l}35.2 \% \\
(N=96)\end{array}$ & $34.66^{* *}$ & $\begin{array}{c}75.9 \% \\
(N=158)\end{array}$ & $\begin{array}{l}24.1 \% \\
(N=50)\end{array}$ & $22.28 * *$ & 3.80 \\
\hline $\begin{array}{l}\text { 32. Amplío la información } \\
\text { con bibliografía comple- } \\
\text { mentaria }\end{array}$ & $\begin{array}{c}90.0 \% \\
(N=245)\end{array}$ & $\begin{array}{c}10.0 \% \\
(N=27)\end{array}$ & $250.56 * *$ & $\begin{array}{c}89.0 \% \\
(N=185)\end{array}$ & $\begin{array}{c}11.0 \% \\
(N=23)\end{array}$ & $49.95 * *$ & .08 \\
\hline $\begin{array}{l}\text { 33. Tengo dificultades en } \\
\text { seguir las explicaciones } \\
\text { del profesor/a en clase }\end{array}$ & $\begin{array}{c}96.7 \% \\
(N=263)\end{array}$ & $\begin{array}{l}3.3 \% \\
(N=9)\end{array}$ & $342.72 * *$ & $\begin{array}{c}98.8 \% \\
(N=206)\end{array}$ & $\begin{array}{l}1.2 \% \\
(N=2)\end{array}$ & $80.05 * *$ & 1.08 \\
\hline
\end{tabular}

$* p<.05, * * p<.01$

Estrategias de aprendizaje después del estudio, en la diplomatura de Magisterio

En la Tabla 7 se presentan las frecuencias de primero y tercero en cada uno de los ítems relacionados con las estrategias de aprendizaje después del estudio. Con respecto al análisis de los alumnos de primero, aparecen diferencias significativas en todos los ítems, 
excepto en el 56, relativo a la atribución de las calificaciones obtenidas al propio estudio y esfuerzo. En general, los alumnos de primero no suelen recordar lo estudiado después del examen $(56.3 \%)$, se ponen nerviosos cuando tienen un examen $(62.2 \%)$, no comienzan a contestar al examen hasta que lo han leído por completo (73.3\%), repasan el examen antes de ser entregado (77.9\%), no suelen comprobar el examen con los apuntes al salir (56.1\%) y están satisfechos con las calificaciones obtenidas (71.5\%).

El análisis de las respuestas de último curso encuentra diferencias significativas en los ítems 53, 54 y 57, es decir, los estudiantes de tercero no suelen comenzar por la primera pregunta del examen sin leer el resto $(82.7 \%)$, repasan frecuentemente las respuestas antes de entregar el examen (75.6\%) y se encuentran satisfechos con las calificaciones obtenidas en el último curso $(60.5 \%)$.

Por último, el análisis en función del curso respecto a las estrategias de aprendizaje después del estudio (ver Tabla 7) no muestra diferencias significativas, exceptuando los ítems 52 y 57 . En ese sentido, los estudiantes de primero se muestran más satisfechos con las calificaciones obtenidas en el curso anterior que los estudiantes de tercero ( $71.5 \%$ frente a $60.5 \%$; $\left.C h i^{2}=3.87, p<.05\right)$, no obstante, se ponen con más frecuencia nerviosos frente a un examen que los estudiantes de último curso (62.2\% vs. $\left.47.6 \% ; C h i^{2}=6.04, p<.05\right)$.

Tabla 7. Porcentaje, Chi-Cuadrado de las cuestiones referidas a las Estrategias de Aprendizaje después del estudio, por curso, en la diplomatura de Magisterio

\begin{tabular}{|c|c|c|c|c|c|c|c|}
\hline \multirow{2}{*}{$\begin{array}{l}\text { ESTRATEGIAS DE } \\
\text { APRENDIZAJE DES- } \\
\text { PUÉS DEL ESTUDIO }\end{array}$} & \multicolumn{3}{|c|}{ Primer Curso } & \multicolumn{3}{|c|}{ Tercero Curso } & \multirow[t]{2}{*}{$C h i^{2}$} \\
\hline & $\begin{array}{l}\text { No Fre- } \\
\text { cuente }\end{array}$ & Frecuente & $C h i^{2}$ & $\begin{array}{l}\text { No Fre- } \\
\text { cuente }\end{array}$ & Frecuente & $C h i^{2}$ & \\
\hline $\begin{array}{l}\text { 51. Suelo recordar lo } \\
\text { estudiado después del } \\
\text { examen }\end{array}$ & $\begin{array}{c}56.1 \% \\
(N=153)\end{array}$ & $\begin{array}{c}43.9 \% \\
(N=119)\end{array}$ & $6.35 *$ & $\begin{array}{l}47.0 \% \\
(N=98)\end{array}$ & $\begin{array}{c}53.0 \% \\
(N=110)\end{array}$ & .30 & 2.42 \\
\hline $\begin{array}{l}\text { 52. Cuando tengo un } \\
\text { examen me pongo nervio- } \\
\text { so/a }\end{array}$ & $\begin{array}{c}37.8 \% \\
(N=103)\end{array}$ & $\begin{array}{c}62.2 \% \\
(N=169)\end{array}$ & $23.20 * *$ & $\begin{array}{c}52.4 \% \\
(N=109)\end{array}$ & $\begin{array}{l}47.6 \% \\
(N=99)\end{array}$ & .20 & $6.04 *$ \\
\hline $\begin{array}{l}\text { 53. Cuando realizo un } \\
\text { examen comienzo por la } \\
\text { primera pregunta sin leer } \\
\text { el resto }\end{array}$ & $\begin{array}{c}73.3 \% \\
(N=199)\end{array}$ & $\begin{array}{l}26.7 \% \\
(N=73)\end{array}$ & $85.21 * *$ & $\begin{array}{c}82.7 \% \\
(N=172)\end{array}$ & $\begin{array}{l}17.3 \% \\
(N=36)\end{array}$ & $34.68 * *$ & 3.18 \\
\hline $\begin{array}{l}\text { 54. Repaso el examen } \\
\text { antes de entregarlo al } \\
\text { profesor/a }\end{array}$ & $\begin{array}{l}22.1 \% \\
(N=60)\end{array}$ & $\begin{array}{c}77.9 \% \\
(N=212)\end{array}$ & $122.04 * *$ & $\begin{array}{l}24.4 \% \\
(N=51)\end{array}$ & $\begin{array}{c}75.6 \% \\
(N=157)\end{array}$ & $21.51 * *$ & .19 \\
\hline
\end{tabular}


55. Al salir de un examen compruebo con los apuntes las respuestas que he dado

56. Considero que las calificaciones obtenidas están en función de mi estudio y esfuerzo 57. Estoy satisfecho con las calificaciones que he obtenido en el curso anterior (o ultimo curso que estudiaste)

$\begin{array}{ccccccr}56.1 \% & 43.9 \% & 5.85 * & 50.0 \% & 50.0 \% & & \\ (N=153) & (N=119) & & (N=104) & (N=104) & .00 & \\ & & & & & & \\ & & & 47.6 \% & 52.4 \% & .20 & .02 \\ 48.3 \% & 51.7 \% & .43 & \left.\begin{array}{c}(N=99) \\ (N=131)\end{array}\right)(N=141) & & (N=109) & .20\end{array}$

$\begin{array}{lcccccc}28.5 \% & 71.5 \% & 72.37 * * & 39.5 \% & 60.5 \% & 3.57 * & 3.87 * \\ (N=78) & (N=194) & & (N=82) & (N=126) & & \end{array}$
$* p<.05, * * p<.01$

\section{Discusión}

El objetivo de esta investigación fue realizar un estudio comparativo de la evolución de las estrategias de estudio que los estudiantes de primer y último curso de la licenciatura de Psicología y la diplomatura de Magisterio declaran emplear. En general, los resultados muestran que los estudiantes de Magisterio parecen mejorar sus estrategias de aprendizaje del primer al último curso mientras que los estudiantes de Psicología muestran un patrón inverso. Respecto a los alumnos de Magisterio, se corroboran los resultados hallados en otras investigaciones con estudiantes universitarios de esta titulación (Camarero et al., 2000; GarcíaBerbén, 2005; Martínez-Otero y Torres, 2005), los cuales apuntan hacia una menor planificación del aprendizaje, un enfoque superficial del mismo y un empleo menos variado y eficaz de las estrategias de aprendizaje en los primeros cursos universitarios. Sin embargo, es sorprendente y contrario a lo esperado, lo que ocurre en los resultados que hemos hallado en el presente trabajo respecto a los estudiantes de primer y último curso de Psicología. Las diferencias observadas pueden ser debidas a los distintos tipos de pruebas empleadas y variables tenidas en cuenta en las diferentes investigaciones. Además, ha de tenerse en cuenta que difiere el último curso de la diplomatura en Magisterio y de la licenciatura en Psicología, pues la primera únicamente tiene tres cursos mientras que son cinco en la segunda. Sería interesante recoger información de los alumnos de tercer curso de Psicología para, de este modo, poder comparar las puntuaciones obtenidas por el alumnado en el mismo curso. Este aspecto puede ser relevante para la interpretación de los resultados obtenidos y sería interesante para futuras investigaciones.

El análisis detallado en cada titulación y curso indica que las diferencias vienen dadas fundamentalmente en las cuestiones referidas al "Lugar y condiciones de estudio" para los 
estudiantes de Psicología y tanto en las "Estrategias de aprendizaje antes del estudio" como en las "Estrategias de aprendizaje después del estudio" para los de ambas titulaciones. En este sentido, tomados en su conjunto, el lugar y las condiciones de estudio de los alumnos universitarios de la licenciatura de Psicología son adecuadas, como se pone de manifiesto en las estrategias de apoyo de las condiciones físicas y ambientales de aprendizaje que utilizan (lugar fijo, con ordenador, temperatura agradable, sin ruido y con iluminación preferentemente natural) así como en el empleo de estrategias positivas de regulación de su ambiente de estudio (Carrasco, 2004, Pintrich et al., 1991). Sin embargo, son los alumnos de primer curso los que muestran, en mayor medida que los de quinto, un mejor control sobre el lugar y condiciones de estudio para las cuestiones descritas, tal vez debido a que se encuentran en su primer año de estudios universitarios y prestan una mayor atención a la incidencia que estas cuestiones puedan tener en su rendimiento académico.

Además, los estudiantes de quinto de Psicología fotocopian los apuntes de otros compañeros en mayor medida que los de primero, no es frecuente que amplíen sus apuntes de clase con bibliografía complementaria, suelen recordar lo estudiado después del examen con menos frecuencia y no es habitual que comprueben las respuestas dadas al examen después del mismo cotejándolas con los apuntes. Una explicación a estos resultados puede venir dada porque en los primeros cursos los alumnos conocen menos el contenido de las asignaturas y los procedimientos que siguen los profesores para explicarlas, por lo que toman más notas y completan sus apuntes, además de repasar con más profundidad. Con el paso de los cursos, los alumnos conocen el contenido y tienen más experiencia a la hora de estudiar y, sobre todo, de examinarse, por lo que es probable que sean más pragmáticos y preparen únicamente el contenido que necesitan para aprobar las asignaturas. Sin embargo, para su constatación, sería necesario analizar en profundidad el tipo de evaluación empleado en cada titulación y curso, lo cual incluiría la existencia y tipo de exámenes, además de si entre las metas del alumnado universitario se encuentra principalmente obtener calificaciones positivas, lo que en muchos casos se traduce en aprobar la asignatura de la forma más cómoda y en el menor tiempo posible (Alonso, 2001; Huertas y Agudo, 2003) y si se ha potenciado, desde dicha evaluación, el empleo de un enfoque superficial del aprendizaje por parte del alumnado (Biggs, 2001; Mateos y Peñalba, 2003, Pérez et al., 2003). También sería interesante revisar las estrategias y metodologías docentes que implementa el profesorado, esto es, si fomentan el aprendizaje autónomo, colaborativo y crítico del alumnado o, por el contrario, un aprendizaje mecánico y más cercano a lo memorístico centrado casi exclusivamente en el examen o exámenes de la asig- 
natura. Esto último contrastaría con el énfasis que se ha puesto en los últimos años en las competencias docentes del profesorado universitario (Imbernón, 2004; Torrego, 2004; Zabalza, 2003, 2006) así como en la necesidad de atender a su formación para la docencia universitaria (Madrid, 2005; Marcelo, 2008; Margalef y Álvarez, 2005; Villar-Angulo, 2004).

En la diplomatura de Magisterio, por su parte, tan sólo se obtuvieron diferencias estadísticamente significativas entre los dos cursos a la hora de fotocopiar los apuntes de otros compañeros, siendo menos frecuente en primer curso por las razones anteriormente descritas. Por el contrario, los alumnos de primero están más satisfechos con las calificaciones obtenidas el último curso y se ponen más nerviosos cuando tienen un examen que los de tercero. Dado que el tránsito de la educación preuniversitaria a la cultura universitaria implica múltiples cambios para adaptarse al nuevo contexto y la adopción de diferentes estrategias de afrontamiento, en algunos casos muy distintas a las que ya se poseían, para superar con éxito las nuevas demandas planteadas, es esperable encontrar que sean los estudiantes de primer curso los que experimentan un mayor nivel de ansiedad ante los exámenes (Fisher y Hood, 1987; Ragheb y McKinney, 1993; Rocha-Sing, 1994; Santacreu, 1991).

En ambas titulaciones se encuentran, además, patrones similares en determinadas cuestiones relativas a las estrategias empleadas tanto antes como después del aprendizaje. De este modo, la toma de apuntes de las explicaciones de los profesores es el procedimiento habitual para recopilar la información a estudiar, lo cual coincide con lo encontrado en otros estudios (Castelló y Monereo, 1999; Monereo y Pérez-Cabaní, 1999), y no se experimentan dificultades para seguir las explicaciones del profesor en clase. Además, aunque no es una conducta frecuente, del primer al último curso se experimenta un incremento en la fotocopia de apuntes de otros compañeros. Igualmente, los alumnos suelen repasar el examen antes de entregarlo.

Un aspecto relevante que merece la pena destacar es que, a pesar de que la satisfacción general con las calificaciones obtenidas, por parte de los estudiantes participantes en nuestro estudio, corrobora los resultados obtenidos en otras investigaciones (Herrera, 2010; Núñez et al., 1998), en ambas titulaciones los estudiantes de los últimos cursos se encuentran menos satisfechos con sus calificaciones, lo cual puede ser debido a la presión experimentada por encontrarse en el último curso de la titulación. 
Para finalizar, es relevante indicar que este estudio ha de ser tomado como una investigación que, de forma descriptiva, ha intentado aproximarse al análisis de las estrategias de aprendizaje que el alumnado universitario indica emplear atendiendo a dos variables de comparación (Titulación y Curso), aunque somos conscientes de sus limitaciones. En primer lugar, los valores obtenidos en el tamaño del efecto son muy bajos, lo cual puede indicar que las diferencias estadísticamente significadas halladas hay que tomarlas con cierta precaución. En segundo lugar, son múltiples las variables, tanto individuales (Bruinsma, 2004; Valle et al., 2006; Wolters, 2004) como contextuales (Cope y Staehr, 2005; Jansen, 2004), y las interacciones entre ellas (De la Fuente y Justicia, 2007; De la Fuente et al., 2008), que la literatura científica indica que son relevantes en este campo de investigación, por lo que en futuras investigaciones deberíamos atender a dichas variables e interacciones. Por último, para evitar la influencia del instrumento de evaluación, también podría ser positivo utilizar más instrumentos de medida, no solamente otros cuestionarios sino, por ejemplo, autoinformes, que evalúen las estrategias de aprendizaje del alumnado con el objeto de comprobar y relacionar los resultados que se obtienen mediante los diferentes instrumentos (Lonka, Olkinuora y Mäkinen, 2004; Martín, García, Torbay y Rodríguez, 2007; Núñéz, Solano, González-Pienda y Rosario, 2006).

\section{Agradecimientos}

El presente trabajo ha sido realizado dentro del Proyecto de Investigación "Estudio exploratorio de las estrategias de aprendizaje del alumnado universitario. Implicaciones para la construcción del EEES”, gracias a la financiación del Plan Propio de Investigación de la Universidad de Granada: Programa 20. Financiación por Objetivos. Contrato-programa entre el Vicerrectorado de Política Científica e Investigación de la Universidad de Granada y el Colectivo de Grupos de Investigación de la Facultad de Educación y Humanidades del Campus Universitario de Melilla (Universidad de Granada). 


\section{Referencias}

Alonso, J. (1995). Motivación y aprendizaje en el aula. Cómo enseñar a pensar. Madrid: Santillana.

Alonso, J. (2001). Motivación y estrategias de aprendizaje. En A. García-Valcárcel (Coord.), Didáctica universitaria (pp. 79-111). Madrid: La Muralla.

Álvarez, I. (2008). Evaluación del aprendizaje en la universidad: una mirada retrospectiva y prospectiva desde la divulgación científica. Electronic Journal of Research in Educational Psychology, 6, 235-272. Disponible en http://www.investigacionpsicopedagogica.org/revista/articulos/14/espannol/Art_14_228.pdf (Consultado el $12 / 10 / 2010)$.

Amaya, J. y Prado, E. (2007). Estrategias de aprendizaje para universitarios. Un enfoque constructivista. Sevilla: Trillas.

Barbero, M.I., Vila, E. y Suárez, J.C. (2003). Psicometría. Madrid: Universidad Nacional de Educación a Distancia.

Benthan, S. (2002). Psychology and Education. New York: Routledge.

Biggs, J. (2001). Enhancing learning: a matter of style of approach? En R. J. Sternberg y L. F. Zhang, Perspectives on Thinking, Learning and Cognitive Style (pp. 73-102). London: LEA.

Boekaerst, M., Pintrich, P.R. y Zeidner, M. (2000). Handbook of Self-Regulation. San Diego: Academic Press.

Boekaerts, M. (1997). Self-regulated Learning: A new concept embraced by researchs, policy makers, educators, teachers, and students. Learning and Instruction, 7(2), 161-186.

Brockbank, A. y McGill, I. (1998) Facilitating Reflective Learning in Higher Education. London: Society for Research into Higher Education.

Bruinsma, M. (2004). Motivation, cognitive processing and achievement in higher education. Learning and Instruction, 14, 549-568.

Burón, J. (1995). Motivación y aprendizaje. Bilbao: Mensajero.

Camarero, F., Martín, F. y Herrero, J. (2000). Estilos y estrategias de aprendizaje en estudiantes universitarios. Psicothema, 12, 615-622.

Cano, F. (2000). Diferencias de género en estrategias y estilos de aprendizaje. Psicothema, 12, 360-367.

Carrasco, J.B. (2004). Estrategias de aprendizaje. Para aprender más y mejor. Madrid: Rialp. 
Castelló, M. y Monereo, C. (1999). El conocimiento estratégico en la toma de apuntes: un estudio en la educación superior. Infancia y Aprendizaje, 22(4), 25-42.

Cope, C. y Staehr, L. (2005). Improving student's learning approaches through intervention in an information systems learning environment. Studies in Higher Education, 30, 181197.

Correa, N., Ceballos, E. y Rodrigo, M.J. (2003). El perspectivismo conceptual y la argumentación en los estudiantes universitarios. En C. Monereo y J.I. Pozo (Eds.), La Universidad ante nueva cultura educativa. Enseñar y aprender para la autonomía (pp. 6378). Madrid: Ed. Síntesis/ICE UAB.

Dansereau, D.F. (1985). Learning strategy research. En J.V. Segal, E. Chipeman y R. Glaser (Eds.), Thinking and learning skills. Vol I: Relating instruction to research (209-240). Hillsdale, NJ: Eribaum.

De la Fuente, J. y Justicia, F. (2007). El modelo DIDEPRO ${ }^{\circledR}$ de regulación de la enseñanza y del aprendizaje: avances recientes. Electronic Journal of Research in Educational Psychology, 5, 535-564. Disponible en http://www.investigacionpsicopedagogica.org/revista/articulos/13/espannol/Art_13_209.pdf (Consultado el 18/12/2009).

De la Fuente, J., Pichardo, M.C., Justicia, F. y García-Berbén, A.B. (2008). Enfoques de aprendizaje, autorregulación y rendimiento en tres universidades europeas. Psicothema, 20(4), 705-711

Delors, J. (1996). La educación encierra un tesoro. Madrid: UNESCO-Santillana.

Entwistle, N.J. (2000). Approaches to studying and levels of understanding: The influences of teaching and assessment. En J.C. Smart (Ed.), Higher Education: Handbook of Theory and Research. Vol. XV (pp. 156-218). Nueva York: Agathon Press.

Fisher, S. y Hood, B. (1987). The stress of the transition to university: a longitudinal study of vulnerability to psychological disturbance and home-sickness. British Journal of Psychology, 79, 1-13.

Fry, H., Ketteridge, S. y Marshall, S. (2003). A handbook for teaching and learning in higher education. Londres: Kogan Page.

Garavalia, L.S. y Gredler, M.E. (2002). Prior achievement aptitude and use of learning strategies as predictors of college student achievement. College Student Journal, 36, 616626.

García-Berbén, A.B. (2005). Estudio de los enfoques de aprendizaje en estudiantes de Magisterio y Psicopedagogía. Electronic Journal of Research in Educational Psychology, 6- 
3(2), 109-126. Disponible en http://www.investigacionpsicopedagogica.org/revista/new/ContadorArticulo.php?70 (Consultado el 28/10/2007).

Gimeno, J. y Pérez, A. I. (1999). Comprender y transformar la Enseñanza. Madrid: Morata. González, C., Valle, A., Rodríguez, S., García, M. y Mendiri, P. (2007). Programa de intervención para mejorar la gestión de los recursos motivacionales en estudiantes universitarios. Revista española de Pedagogía, 237, 237-256.

Hattie, J., Biggs, J. y Purdie, N. (1996). Effects of Learning Skills Interventions on Student Learning: A Meta-Analysis. Review of Educational Research, 66(2), 99-136.

Heikkilä, A. y Lonka, K. (2006). Studying in higher education: students'approaches to learning, self-regulation, and cognitive strategies. Studies in Higher Education, 31(1), 99117.

Herrera, L. (2010). Evaluación de la docencia universitaria. Estudio predictivo de la satisfacción del alumnado con el aprendizaje en la Educación Superior. En M.C. Gómez y S. Grau (Coords.), Evaluación de los aprendizajes en el Espacio Europeo de Educación Superior (pp. 587-604). Alicante: Marfil.

Herrera, L. y Enrique, C. (2008). Proyectos de Innovación en Tutorías en la Universidad de Granada: Análisis de los instrumentos empleados. Profesorado. Revista de Currículum y Formación del Profesorado, 12(2), 1-18. Disponible en http://www.ugr.es/ recfpro/rev122COL5.pdf (Consultado el 07/11/2009).

Herrera, L. y Gallardo, M. A. (2006). Diseño de cuestionarios de evaluación para el alumnado participante en Proyectos de Innovación Tutorial. En M.A. Gallardo, L. Herrera, S. Rodríguez, G. Rojas, D. Seijo, J.L. et al. (Coords.). I Congreso Internacional de Psicopedagogía: Ámbitos de intervención del psicopedagogo (pp. 1-18). Granada: Proyecto de Innovación Docente "Plan de Mejora y Evaluación del Prácticum de Psicopedagogía en Melilla".

Herrera, L. y Lorenzo, O. (2009). Estrategias de aprendizaje en estudiantes universitarios. Un aporte a la construcción del Espacio Europeo de Educación Superior. Educación y Educadores, 12(3), 75-98.

Huertas, J.A. y Agudo, R. (2003). Concepciones de los estudiantes sobre la motivación. En C. Monereo y J.I. Pozo (Eds.), La Universidad ante la nueva cultura educativa. Enseñar y aprender para la autonomía (pp. 45-62). Madrid: Ed. Síntesis/ICE UAB. 
Imbernón, F. (2004). La formación y el desarrollo profesional del profesorado. $\sigma^{a}$ Ed. Barcelona: Graó.

Jansen, E. (2004). The influence of the curriculum organization on study progress in higher education. Higher Education, 47, 411-435.

Justicia, F. y Cano, F. (1993). Concepto y medida de las estrategias y los estilos de aprendizaje. En C. Monereo (Comp.), Las estrategias de aprendizaje: procesos, contenidos e interacción (pp. 113-126). Barcelona: Ediciones Domènech.

Lizzio, A., Wilson, K. y Simons, R. (2000). University Students' Perceptions of the Learning Environment and Academic Outcomes: implications for theory and practice. Studies in Higher Education, 27(1), 27-52.

Lonka, K., Olkinuora, E. y Mäkinen, J. (2004). Aspects and prospects of measuring studying and learning in higher education. Educational Psychology Review, 16, 301-323.

Madrid, J.M. (2005). La formación y la evaluación docente del profesorado universitario ante el Espacio Europeo de Educación Superior. Educatio, 23. Disponible en http://www.um.es/ojs/index.php/educatio/article/viewFile/117/101 (Consultado el 16/11/2008).

Marcelo, C. (2008). El profesor principiante. Inserción a la docencia. Barcelona: Octaedro.

Margalef, L. y Álvarez, J. M. (2005). La formación del profesorado universitario para la innovación en el marco de la integración del Espacio Europeo de Educación superior. Revista de Educación, 337, 51-70

Martí, E. (2003). Conclusiones: el estudiante universitario en el siglo XXI. En C. Monereo y J.I. Pozo (Eds.), La Universidad ante la nueva cultura educativa. Enseñar y aprender para la autonomía (pp. 111-116). Madrid: Ed. Síntesis/ICE UAB.

Martín, E., García, L.A., Torbay, A. y Rodríguez, T. (2007). Estructura factorial y fiabilidad de un cuestionario de estrategias de aprendizaje en universitarios: CEA-U. Anales de Psicología, 23, 1-6.

Martín, E., García, L.A., Torbay, A. y Rodríguez, T. (2008). Estrategias de aprendizaje y rendimiento académico en estudiantes universitarios. International Journal of Psychology and Psychological Therapy, 8(3), 401-412.

Martín, E., Torbay, A., García, L.A. y Rodríguez, N. (2002). Los estudiantes universitarios con un estilo creativo: relación entre creatividad, motivación y estrategias de aprendizaje. Creatividad y Sociedad, 2, 57-65.

Martín, F. y Camarero, F. (2001). Diferencias de género en los procesos de aprendizaje de los universitarios. Psicothema, 13, 598-604. 
Martínez-Otero, V. y Torres, L. (2005). Análisis de los hábitos de estudio en una muestra de alumnos universitarios. Revista Iberoamericana de Educación, 35(7). Disponible en http://www.rieoei.org/deloslectores/927MartinezOtero.PDF (Consultado el 20/12/2007).

Marton, F. y Booth, S. (1997). Learning and awareness. Hillsdale, NJ: Erlbaum.

Marton, F., Dall'Alba, G. y Beaty, E. (1993). Conceptions of learning. International Journal of Educational Research, 19(3), 277-300.

Marton, F. y Säljö, R. (1976). On Qualitative Differences in Learning I. Outcome and Process. British Journal of Educational Psychology, 46, 4-11.

Marton, F., Wen, Q. y Nagle, A. (1996). Views on learning in different cultures: comparing patterns in China and Uruguay. Anales de Piscologia, 12(2), 123-132.

Mateos, M. y Peñalba, G. (2003). Aprendizaje a partir de un texto científico en la universidad En C. Monereo y J.I. Pozo (Eds.), La Universidad ante nueva cultura educativa. Enseñar y aprender para la autonomía (pp. 79-92). Madrid: Ed. Síntesis/ICE UAB.

Mayer, R. (2004). Psicología de la educación II. Enseñar para un aprendizaje significativo. Madrid: Prentice Hall.

Mayor, J., Suengas, A. y González, J. (1995). Estrategias metacognitivas. Aprender a aprender y aprender a pensar. Madrid: Síntesis.

Monereo, C. (Coord.) (1994). Estrategias de enseñanza y aprendizaje. Formación del profesorado y aplicación en la escuela. Barcelona: Graó.

Monereo, C. (1999a). Enseñar a aprender y a pensar en la Educación Secundaria: las estrategias de aprendizaje. En C. Coll (Coord.), Psicología de la Instrucción: la enseñanza y el aprendizaje en la Educación Secundaria (pp. 69-103). Barcelona: Horsori/ICE UB.

Monereo, C. (1999b). El asesoramiento psicopedagógico en el ámbito de las estrategias de aprendizaje: niveles de intervención. En J.I. Pozo y C. Monereo (Eds.), El aprendizaje estratégico (pp. 357-373). Madrid: Santillana.

Monereo, C. (Coord.) (2000). Las estrategias de aprendizaje. Madrid: Aprendizaje/Visor.

Monereo, C. (Coord.) (2001). Ser estratégico y autónomo aprendiendo. Unidades de enseñanza estratégica para la ESO. Barcelona: Graó.

Monereo, C. (Comp.) (2006). Experiencias de autorregulación en la Educación Secundaria. Barcelona:

Monereo, C. y Castelló, M. (1997). Las estrategias de aprendizaje. Cómo incorporarlas a la práctica educativa. Barcelona: Edebé. 
Monereo, C. y Pérez-Cabaní, M.L. (1996). La incidencia de la toma de apuntes sobre el aprendizaje significativo. Un estudio en la enseñanza superior. Infancia y Aprendizaje, $73,65-86$.

Moreira, M.A. (2000). Aprendizaje Significativo: Teoría y Práctica. Madrid: Visor.

Nisbet, J. y Shucksmith, J. (1987). Estrategias de aprendizaje. Madrid: Santillana.

Núñez, J.C., González-Pienda, J.A., García, M., González-Pumariega, S., Roces, C. et al. (1998). Estrategias de aprendizaje, autoconcepto y rendimiento académico. Psicothema, 10, 97-109.

Núñez, J.C., Solano, P., González-Pienda, J.A. y Rosario, P. (2006). Evaluación de los procesos de autorregulación mediante autoinforme. Psicothema, 18, 353-358.

Perez-Cabaní, M.L., Carretero, R., Palma, M. y Rafel, E. (2000). La evaluación de la calidad del aprendzaje en la universidad. Infancia y Aprendzaje, 91, 5-30

Pérez, P., Pozo, J.I. y Rodríguez, B. (2003). Concepciones de los estudiantes Universitarios sobre el aprendizaje. En C. Monereo y J.I. Pozo (Eds.), La Universidad ante la nueva cultura educativa. Enseñar y aprender para la autonomía (pp. 33-44). Madrid: Ed. Síntesis/ICE UAB.

Pintrich, P. y García, T. (1993). Intraindividual differences in students' motivation and selfregulated learning. German Journal of Educational Psichology, 7(3), 99-107.

Pintrich, P., Smith, D., García, T. y McKeachie, W. (1991). A manual for the use of the Motivated Strategies for Learning Questionnaire (MSLQ). Michigan: University of Michigan.

Pintrich, P.R. (2004). A conceptual framework for assessing motivation and self-regulated learning in college students. Educational Psychology Review, 16, 385-407.

Ragheb, M.G. y McKinney, J. (1993). Campus recreation and perceived academic stress. Journal of College Student Development, 34, 5-10.

Riding, R.J. y Rayner, S.G. (2000). International Perspectives on Individual Differences. Cognitive Styles. Stamford: Ablex.

Riding, R.J. y Sadler, E. (1997). Cognitive Style and Learning Strategies: Some Implications for Training Design. International Journal of Training and Development, 1(3), 199208.

Rocha-Sing, I. A. (1994). Perceveid stress among graduate student: Development and validation of the Graduate Stress Inventory. Educational and Psychological Measurement, 54(3), 714-727. 
Rozendal, J.S., Minnaert, A. y Boekaerts, M. (2005). The influence of teacher perceived administration of self-regulated learning on students' motivation and information processing. Learning and Instruction, 15(2), 141-160.

Säljö, R. (1979). Learning about learning. Higher Education, 8, 443-451.

Santacreu, J. (1991). Psicología Clínica y Psicología de la Salud. Marcos teóricos y modelos. Revista de Psicología de la Salud, 3(1), 3-20.

Schmeck, R.R. (1988). An introduction to strategies and styles of learning. En R.R. Schmeck (Ed.), Learning strategies and learning styles (pp. 3-19). Nueva York: Academic Press.

Sternberg, R.J. (1990). Thinking styles: keys to understanding student performance. Phi Delta Kappan, 71, 366-371.

Torrego, L. (2004). Ser profesor universitario, ¿un reto en el contexto de la convergencia europea? Un recorrido por declaraciones y comunicados. Revista Interuniversitaria de Formación del Profesorado, 18(3), 259-268.

Trigwell, K., Prosser, M. y Waterhouse, F. (1999). Relations between teachers' approaches to teaching and students' approaches to learning. Higher Education, 37, 57-70.

Valle, A., Barca, A., González, R. y Núñez, J.C. (1999). Las estrategias de aprendizaje: revisión teórica y conceptual. Revista Latinoamericana de Psicología, 31, 425-461.

Valle, A., Cabanach, R.G., Rodríguez, S., Núñez, J.C. y González-Pienda, J.A. (2006). Metas académicas, estrategias cognitivas y estrategias de autorregulación del estudio. Psicothema, 18, 165-170.

Villar-Angulo, L.M. (Coord.) (2004). Programa para la mejora de la docencia universitaria. Madrid: Pearson Prentice Hall.

Weinstein, C., Husman, J. y Dierking, D. (2000). Self regulation interventions with a focus on learning strategies. En M. Boekaerst, P.R. Pintrich y M. Zeidner (Comps.), Handbook of Self-Regulation (pp. 727-747). San Diego: Academic Press.

Winne, P.H. (1997). Experimenting to Bootstrap Self-regulated Learning. Journal of Educational Psychology, 89(3), 397-410.

Wolters, C.A. (2004). Advancing achievement goal theory: using goals structures and goal orientations to predict students' motivation, cognition and achievement. Journal of Educational Psychology, 96, 236-250.

Wolters, C.A. y Pintrich, P. (1998). Contextual differences in student motivation and selfregulated learning in mathematics, english and social studies classrooms. Instructional Science, 26, 27-47. 
Zabalza, M.A. (2003). Competencias docentes del profesorado universitario: calidad y desarrollo profesional. Madrid: Narcea.

Zabalza, M.A. (2006). Buscando una nueva hoja de ruta en la formación del profesorado. Revista de Educación, 340, 51-58.

Zimmerman, B.J. (2000). Achieving academic excellence: A self-regulatory perspective. En M. Ferrari (Ed.), The pursuit of excellence through education. The educational psychology series (pp.85-100). Mahwah, NJ: LEA.

Zimmerman, B.J. (2002). Becoming a self-regulated learner: an overview. Theory into Practice, 41(2), 64-70.

Zimmerman, B.J. y Kitsantas, A. (1997). Developmental phases in self-regulation: shifting from process goals to outcome goals. Journal of Educational Psychology, 89, 29-36. 
Lucía Herrera Torres et al.

[Página en blanco por razones de paginación] 